\title{
PESQUISA SOBRE ENSINO E APRENDIZAGEM: um convite-desafio para professores de linguística
}

Ricardo Joseh Lima

(UERJ)

\begin{abstract}
BISHOP-CLARK, Cathy; DIETZ-UHLER, Beth. ENGAGING IN THE SCHOLARSHIP OF TEACHING AND LEARNING: a guide to the process, and how to develop a project from start to finish.
\end{abstract}

Sterling, Virginia: Stylus Publishing, 2012

O professor de Linguística se prepara para oferecer um curso introdutório e se depara com uma série de obras que podem auxiliá-lo nessa tarefa: "Manual de Linguística", "Introdução à Linguística", "Linguística, o que é isso?", "Novos caminhos da Linguística" e "Novos caminhos da Linguística" são alguns dos títulos a sua disposição. No entanto, há uma percepção de que eles podem não ser suficientes. Afinal, todos lhe oferecem conteúdos diversos, alguns até fornecem exercícios pontuais, mas não permitem uma apreensão de como seus alunos estão assimilando e compreendendo os conteúdos apresentados, nem sobre sua metodologia de ensino ser ou não adequada a essa tarefa. Apresentar uma proposta que dê conta de responder a esses tipos de situação é um dos objetivos de Bishop-Clark e Dietz-Uhler no livro Engaging in the scholarship of teaching and learning: a guide to the process, and how to develop a project from start to finish. O outro objetivo de destaque é fazer essa apresentação em forma de manual, com exemplos e possibilidades de praticar o que está sendo exposto.

Contando com nove capítulos e quatro apêndices, o livro constitui um guia para a realização de projetos na área de Pesquisa sobre Ensino e Aprendizagem $^{1}$, doravante PEA. Esse guia foi pensado para aquele professor que se identifica com a situação que abre essa resenha e se interessa 
em buscar respostas concretas. As autoras frisam, desde o início do livro, e nesse momento entendemos por que se trata de um convite e ao mesmo tempo de um desafio, que essa busca deve acontecer de um modo formal, objetivo, observando os rigores do método científico e as diretrizes que toda e qualquer pesquisa acadêmica deve seguir. Assim, fica o professor/ leitor convidado a se inteirar e fornecer um retorno ao desafio proposto pela PEA. Para a sorte do professor/leitor, as autoras fazem desse convite e do desafio uma leitura fácil, simples e ágil.

Os dois primeiros capítulos apresentam e discutem definições de PEA (uma delas está descrita na busca mencionada no parágrafo anterior) e ressaltam a importância da realização desse tipo de trabalho. O livro abre com as histórias profissionais que levaram as autoras a se interessar e ingressar nessa área de pesquisa, para em seguida salientar o quanto o trabalho com PEA nada deve aos demais trabalhos do meio acadêmico. $\mathrm{O}$ terceiro capítulo marca uma transição para a sequência de cinco capítulos que constituem o guia anunciado no subtítulo do livro e ilustra o que vai acontecer em cada um deles: a escolha de uma pergunta de pesquisa (uma nova técnica de ensino vai ajudar na aprendizagem de um tema complexo?), a colocação em prática dessa pergunta, a utilização de algum método (prova ou entrevista) para medir grau de sucesso da nova técnica, a comparação de resultados do método utilizando-se ou não a nova técnica e, por fim, a divulgação dos resultados da pesquisa.

Os cinco capítulos possuem a mesma estrutura: apresentação, desenvolvimento com exemplos, ideias de como envolver os alunos na pesquisa e um formulário com os principais itens de cada capítulo de que o pesquisador deve estar consciente, além de um formulário preenchido para servir como exemplo. Desse modo, para um professor que já possui alguma experiência com os princípios da pesquisa acadêmica, os capítulos servem para visualizar como seria a aplicação desses princípios. Já para o professor iniciante na pesquisa ou sem experiência, trata-se de um valoroso material, explicado passo a passo, em que se apontam benefícios e problemas de cada etapa da pesquisa acadêmica.

A primeira etapa consiste na elaboração da pergunta que vai gerar a pesquisa. Especial atenção deve ser aferida nesse momento, até para os professores experientes em pesquisa acadêmica, uma vez que aqui a área de PEA apresenta algumas particularidades. Basicamente, o professor interessado nessa área deve estar consciente das limitações que seu cotidiano de trabalho na instituição lhe impõe e, desse modo, a pergunta 
deve se relacionar com essas limitações. Realizar uma pesquisa comparando várias técnicas de ensino em diversas turmas é bastante atraente, mas é factível? Que tal iniciar com perguntas mais específicas em apenas uma turma? As autoras fazem várias sugestões em espectros diferentes de realidade de trabalho e enfatizam a necessidade extrema da realização, nesse ponto, de uma revisão aprofundada da literatura sobre o assunto de escolha do professor, que nesse momento, está em vias de se tornar pesquisador sobre Ensino e Aprendizagem. Tal ênfase é um exemplo de como esse tipo de trabalho pretende ser considerado pesquisa acadêmica, uma vez que a revisão da literatura é um de seus princípios básicos.

O quinto capítulo apresenta a divisão clássica entre pesquisa quantitativa e qualitativa e expõe em detalhes cada um desses modos de fazer pesquisa. Sugere a realização de um estudo piloto a aponta, para a área de PEA, os principais modelos de pesquisa: Descritiva, Estudo de Caso, Observacional, Entrevista, Grupo, Experimental, Quasi-Experimental e Levantamento. As autoras ilustram cada modelo, destacando a relação entre eles e a possibilidade de um trabalho em PEA utilizar mais de um desses métodos ou uma combinação dos mesmos.

A coleta de dados é o tema do sexto capítulo. As autoras lembram que todo professor coleta dados todos os dias, ao final de suas aulas. No entanto, isso é feito de modo informal, assistemático e, portanto, sem validade científica. Os dados de PEA devem ser como os das demais pesquisas: possuir confiabilidade, serem passíveis de ser reproduzidos e serem robustos. Testes, questionários e análise de comportamento são técnicas sugeridas para dar conta desses parâmetros. Questões sobre quem vai coletar os dados, se o próprio professor ou alguém externo à pesquisa, são levantadas e relacionadas com a questão ética mais ampla de condução de pesquisa com seres humanos. A necessidade de haver o que conhecemos como Termo de Consentimento Livre e Esclarecido e de se submeter a pesquisa a um Comitê de Ética é ressaltada no fim do capítulo.

O sétimo capítulo aborda como se procede a análise de dados em modelos qualitativos e quantitativos. As autoras ressaltam que o capítulo foi escrito tendo em vista o professor iniciante nesse trabalho e que os conteúdos expostos não o capacitam para a realização de análises, sendo a ajuda de colegas com experiência em análise de dados crucial para tanto.

O oitavo capítulo se concentra nas formas de divulgação do trabalho em PEA. Elas vão desde as comunicações informais dentro do 
Departamento ao qual o professor pertence, passando por comunicações formais em sua instituição de trabalho até as tradicionais apresentações em congresso e publicações de artigo. A escolha de qual situação de divulgação será utilizada dependerá do contexto em que o professor se insere. Uma instituição que carece de cultura a respeito de PEA pode exigir do mesmo que ele realize uma palestra. Professores que já possuem uma estrada em pesquisa e publicações podem se encaminhar para publicação em revistas especializadas.

O nono e último capítulo do livro levanta os principais desafios para se iniciar um trabalho em PEA: a indisponibilidade de tempo, a falta de informação sobre esse tipo de trabalho ser pesquisa e a ausência de suporte institucional. Para cada um dos desafios, as autoras apresentam soluções: pode-se conjugar a pesquisa que o professor já vem fazendo com a de Ensino e Aprendizagem, fornecendo a esta, aos poucos, um espaço maior; fazer um levantamento de outras instituições que levam em conta trabalhos realizados nessa área como pontuação para currículo; e demonstrar os benefícios que a PEA pode oferecer para a instituição. O capítulo se encerra com uma história de uma professora que se interessou por essa área, inicialmente, apenas por curiosidade e como a continuidade de seu trabalho gerou uma bolsa de pesquisa para ela e seus colegas.

Completam a obra quatro apêndices: o primeiro se destina a listar as conferências sobre PEA; o segundo os periódicos especializados nessa área; o terceiro levanta os periódicos sobre disciplinas que podem servir como meio de divulgação para trabalhos em PEA e o quarto lista periódicos sobre ensino na Educação Superior.

O término da leitura da obra de Bishop-Clark e Dietz-Uhler tende a produzir no leitor sentimentos conflitantes. O primeiro pode ser o de encanto em descobrir uma área tão delineada e compromissada como a PEA, que vem substituir o "será que eles entenderam as diferentes propostas sobre aquisição da linguagem?" ou "como fazer para melhorar o ensino sobre variação linguística?” por uma prática de pesquisa compromissada. O segundo é o questionamento de por que não se encontra praticamente nenhuma referência a essa área no Brasil ${ }^{2}$, o que pode ser explicado com a proposição de que os desafios abordados no nono capítulo sequer foram levantados seriamente para que se possa obter respostas consistentes aos mesmos. A utilização de histórias pessoais, por exemplo, não auxiliaria na percepção de que a PEA é uma área de pesquisa como qualquer outra. O desafio maior, no entanto, nos parece 
ser a questão da divisão do tempo: conseguiria o professor que já se encontra inserido em uma linha de pesquisa, com seu projeto em andamento, dividir esse trabalho com outro, que demanda os mesmos rigores científicos? Só o tempo parece ter a resposta para essa pergunta, pois o mesmo revelará quantos aceitaram o convite-desafio proposto e a partir disso obtiveram resultados positivos em suas práticas de sala de aula. NOTAS

${ }^{1} \mathrm{O}$ termo original é Scholarship of Teaching and Learning. A tradução é minha, por não ter encontrado versões difundidas de tradução desse termo, um assunto ao qual retorno no final do texto.

${ }^{2}$ Considerando que um trabalho desenvolvido por mim e uma orientanda não pode contar, apenas PALIS, Gilda. A PESQUISA SOBRE A PRÓPRIA PRÁTICA NO ENSINO DE MATEMÁTICA EM CURSOS SUPERIORES. 2008., um texto sem referência ao local de publicação. Os demais resultados vêm de pesquisas realizadas em Portugal.

Recebido em: 29/01/2017

Aceito em: 13/06/2017 